\title{
DIE UNIVERSITEIT EN BEROEPSOPLEIDNG
}

\author{
Dr. J.G. Garbers, President van die R.G.N.
}

By elke gradedag is daar by die betrokkenes die neiging om terug te dink aan die pad wat hul bekroning voorafgegaan het.

Diegene wat hulle met die volwassewording besig hou, weet maar al te goed aan hoeveel voorwaardes oor baie jare voldoen moes word om 'n jongmens by hierdie mylpaal te kon bring. Aan baie kwaliteitseise in die opvoeding moes voldoen word. Veel meer as voeding, versorging en die voorsien van middele deur die ouers was nodig. Ook 'n bepaalde kwaliteit kontak en gesprekvoering met mekaar en wedersydse aanvaarding en positiewe verwagtings van mekaar was nodig. Geleenthede moes voorsien en benut word, selfstandigheid moes deur die ouers toe. gelaat en deur die kinders verdien word, ens.

By daardie graduandi wat al ouer en getroud is, sluit dit ook in 'n lewensmaat wat ondersteun het en moes opoffer.

Gelukkig is die mens egter ook so geskape dat hy hom steeds weer op die toekoms rig. Trouens, dit is so ' $n$ inherente deel van die mens dat wanneer jy 'n bepaalde mylpaal in jou lewe bereik het, jy alreeds by daardie mylpaal verbygeleef het en dit gevolglik wil voorkom asof daardie mylpaal nie meer só belangrik is nie. Hierdie tipiese karaktertrek van die mens is sekerlik die belangrikste eienskap wat lei tot die voortdurende verjonging en dinamiek, nie net in elke mens se persoonlike lewe nie, maar ook in die samelewing. Ek glo dus dat ons graduandi vandag nie net terugkyk en terugdink nie, maar ook en veral aan die toekoms, aan die boeiende uitdagings wat wag, dink - dat hulle dus reeds in 'n belangrike mate verbygegroei het by die graduering of diplomering wat vandag bevestig en gevier word.

Al dink elkeen vanaand miskien hoofsaaklik aan persoonlike ervarings en verhoudings, is 'n geleentheid soos hierdie ook 'n weerspieëling van 'n ander en meer globale samespel van invloede. Ek wil graag enkele van hierdie invloede uitlig omdat hulle so dikwels misgekyk word en hierdie invloede juis van direkte belang is vir ons graduandi wat hulself in meer beroepsgerigte of professionele rigtings

* Rede gelewer by geleentheid van die gradeplegtigheid van die Fakulteit Lettere en Wysbegeerte van die PU vir CHO op 24 Maart 1980. 
bekwaam het.

\section{Veranderinge in die samelewing}

Die hoofkenmerk van die menslike samelewing is dat alles in finale instansie met alles saamhang. Die feit dat 'n groep mense vandag hier beroepsgerigte grade ontvang, is dan ook 'n weerspieëling van sekere veranderinge wat in die samelewing plaasvind. Een van die belangrikste voorbeelde hiervan en wat vanaand hier weerspieël word, is dié van die spesialisering van funksies in die samelewing en die sogenaamde professionalisering wat hom ten opsigte van baie beroepsfunksies in die samelewing afspeel. Dit impliseer bloot dat daar toenemend gespesialiseerde opleiding gegee moet word aan persone wat bepaaide take - wat al meer gespesialiseerd word - in die samelewing moet vervul.

Dit is nie moeilik om te verstaan watter invloed tot hierdie professionalisering aanleiding gee nie. Ten opsigte van elke verband in die samelewing kom daar voortdurend en teen 'n baie hoë tempo nuwe kennis beskikbaar wat vinnig en doeltreffend assimileer moet word, ten einde die betrokke samelewingsverband beter te begryp en om ten opsigte daarvan ten beste diens te lewer en/of dit ten beste te orden en te stuur. Dink maar aan die kennisvermeerdering wat spesifiek die biblioteek-, inligtings- en kommunikasiekunde nodig gemaak het. Nie net die kennisontploffing nie, maar ook die tegnologiese ontploffing waardeur die basiese wetenskaplike insigte in die daaglikse lewe tot toepassing gebring word, verloop teen so 'n hoë tempo dat enersyds gedgradueerdes voortdurend herskoling, omskoling of opknapping moet ontvang, en daar andersyds voortdurend aanpassings gemaak moet word in die basiese wetenskappe waaraan studente in hul opleiding blootgestel moet word. Laasgenoemde is in 'n toenemende mate waar in die geesteswetenskaplike rigtings.

Ook die feit dat kommunikasie in so 'n groot mate ontwikkel het dat geografiese versperrings wat die isolasie van groepe veroorsaak, verdwyn het, het daartoe gelei dat groepe mense oor die hele wêreld heen by mekaar betrokke raak. Dít maak veral die wêreld waarin mense leef oneindig ingewikkelder, en dit noodsaak op sy beurt 'n professionalisering van baie dienste wat in die samelewing gelewer word. Die verskeidenheid beroepsgerigte grade wat vanaand in die fakulteit Lettere en Wysbegeerte aangebied word, is by uitstek 'n weerspieëling hiervan. 'n Verdere invloed wat professionalisering noodsaak, is veranderinge in die ekonomiese lewe waardeur ingrypende veranderings in die arbeidsverdeling plaasgevind het, sodat 'n veel groter verskeidenheid beroepe ontwikkel het, werknemers in 'n groter mate in 
winste kan deel, lojaliteite van werknemers teenoor 'n onderneming of werkgewer in 'n veel groter mate vervang word met 'n lojaliteit teenoor sy professionele affiliasies, ens. Binne so 'n dinamiese samelewingsopset vervul beroepsopleiding met die oog op professionalisering - veral op universitêre vlak - 'n sleutelrol. Die tipes grade wat vanaand toegeken word, weerspieël dus ook die feit dat daar in die samelewing sekere behoeftes gegroei het wat enersyds duidelik omskryfbaar is, maar waarvoor die universiteitswese andersyds gevoelig genoeg was om d.m.v. opleiding aan te voldoen.

Maar ook op 'n verdere meer globale en historiese wyse is 'n gradeplegtigheid getuie van 'n besondere samespel van invloede: Hier is vandag graduandi wat die eerste geslag in ' $n$ bepaalde familie is wat 'n universitêre kwalifikasie behaal. Dit weerspieël 'n opvoedkundige opbou wat meesal oor baie geslagte plaasgevind het. Dit is dan ook 'n weerspieêling van die baie belangrike rol wat die totale onderwyssisteem (vanaf pre-primêre tot die tersiêre onderwysvlak) in die Suid-Afrikaanse samelewing speel, om die kultuur-opvoedkundige peil van die totale bevolking te verhoog - 'n terrein waarop Suid-Afrika met reg trots kan wees.

Hierdie feit, nl. dat daar in die Suid-Afrikaanse samelewing haas onbeperkte moontlikhede gebied word om deur studie in die lewe vooruit te gaan, is al deur navorsers aangetoon. Uit gegewens van Projek Talentopname van die RGN, en waarin 67000 standerd ses-leerlinge sedert 1965 opgevolg is, het dit onlangs geblyk dat die eerste sewe persone uit die groep wat doktorsgrade in feitlik minimumtyd behaal het, uit huise gekom het waarvan die ouers self oor die volgende akademiese kwalifikasies beskik het:

$\begin{array}{lll}\text { PERSOON } & \text { BEROEP - VADER } & \text { BEROEP - MOEDER } \\ 1 & \text { Werkvoorman by SAS \& H } & \text { Klerk } \\ 2 & \text { Klerk } & \text { Tikster } \\ 3 & \text { Boukontrakteur } & \text { Tikster } \\ 4 & \text { Predikant } & \text { Onderwyseres } \\ 5 & \text { Ondersoeker by SAS \& H } & \text { Huisvrou (st. '6 behaal) } \\ 6 & \text { Boer } & \text { Huisvrou (st. 8 behaal) } \\ 7 & \text { Majoor SAP } & \text { Verpleegster }\end{array}$

In vergelyking met baie ander lande is die vorderingskanse vir mense in die RSA dus baie gunstig, soos ook hier weer eens duidelik geillustreer word. Dit is uit die aard van die saak vir die Suid-Afrikaanse onderwysstelsel 'n groot pluimpie. 
Waar ons dus by 'n gradeplegtıgheid getuie is van 'n besondere samespel van invloede, is dit geregverdig om stil te staan by die eise wat daar in 'n snelveranderde wêreld gestel word aan die universitêre opleiding van diegene wat die professies moet beman.

\section{Die eise gestel aan beroepsopleiding}

Die opleiding vir daardie beroepe waarvoor universitêre opleiding as voorvereiste geld en wat in ' $n$ meerdere of mindere mate reeds as erkende professies bestaan of vinnig besig is om in dié rigting te beweeg, verkeer onder die spervuur van voortdurende kritiek. Die drie hoofpunte van kritiek is die volgende:

* Die beroepe self en by implikasie die opleiding vir hierdie beroepe is nie in ' $n$ voldoende mate gevoelig vir nuwe probleme en eise wat in die samelewing bestaan nie.

* Die kennis wat beskikbaar is word nie in 'n voldoende mate in die opleiding en gevolglik in die uiteindelike beroepsbeoefening benut nie.

* Geen enkele beroep - veral dié met 'n geesteswetenskaplike basis - kan alle probleme in die samelewing wat tot sy terrein behoort, oplos nie. Die opgeleides toon nie genoeg openheid vir skakeling met ander professies nie en in die opleiding word nie geslaag om die konseptuele grense tussen die dissiplines wat betrokke is, te deurbreek nie. Verder bestaan die gevaar dat met die skepping van outonome professies, grense geskep word wat die ontwikkeling van nuwe professies sal inhibeer.

(Net so terloops: Die toegepaste sosiale of gedragswetenskappe blyk in 'n toenemende mate die noodsaaklike aanvulling te wees wat in feitlik alle ander professies benodig word. Dit is nit moeilik om te begryp nie, want feitlik al die professies benodig beofenaars met diagnostiese vaardighede van sosiale probleme; vaardighede om multi- en interdissiplinêre vaardighede te bou, te lei en te bestuur; vaardighede om met kliënte en beoefenaars van ander professies saam te werk; vaardighede om onderliggende waardes te kan peil wat aan professionele praktyke en tegnologiese ontwikkeling ten grondslag lê; ens. Onnodig om te sê dat dit hoë eise aan en verwagtings van die gedrags- en sosiale wetenskappe stel).

Genoemde lysie van punte van kritiek op die professionele rigtings en die universitêre opleiding vir hierdie rigtings, kan nog veel langer gemaak word. (Byvoorbeeld: 
Opgeleides kan nie samelewingsprobleme wat 'n interdissiplinêre of inter-professionele benadering vereis, hanteer nie; die vereistes van sekere professies en veral die groter-wordende basis van basiese en toegepaste kennis het so 'n konvergerende invloed dat innovasie haas onmoontlik word, behalwe ten opsigte van hoogs-ge spesialiseerde inhoude op die voorposte van die professies en dergelike (Schein, 1972:59 e.v.).

Die meeste van hierdie kritiek kan teruggevoer word na 'n baie sentrale probleem waarmee elkeen worstel wat 'n medemens moet oplei (of beinvloed), naamlik: Watter leerervarings moet uitgesoek word om die student ten beste voor te berei vir die beroep wat hy eendag gaan beoefen? Op hierdie punt sien die werkgewer en die dosent aan die universiteit dikwels nie oog om oog nie. Die werkgewer wil 'n direk-bruikbare produk hê en verwyt al te dikwels die universiteit dat hy vir die student net 'n klomp teorieë leer en dat hulle wat werkgewers is, dan die opgeleide eers weer in die praktiese beroepsituasie moet oplei. Daarteenoor stel die universiteitsdosent dan meesal dat hy nie 'n pasklaar produk kan of selfs durf oplei nie, want enersyds verskil die beroepsituasies waarvoor die student dan opgelei moet word hemelsbreed in verskillende kontekste, en andersyds verander die beroepsituasies - of behoort hulle te verander - sodat hy aan die student eerder 'n algemene akademiese gevormdheid of geskooldheid moet gee sodat die gegradueerde nie alleen in enige gegewe beroepsituasie moet kan innoveer nie, maar ook oor genoegsame akademiese soepelheid beskik om nuwe omstandighede die hoof te bied. Dit spreek vanself dat daar tussen hierdie twee teenpole vele nuanses bestaan. Die vraag ontstaan ook dadelik of die antwoord dan nie dalk lê in 'n gesonde balans tussen die beroepsgerigte en die nie-spesifieke beroepsgerigte komponente van die opleiding nie. Só eenvoudig is die saak ongelukkig nie.

Alvorens daar verder op die wenslikheid van oeroepsgerigte opleiding ingegaan word, laat ons nagaan hoe die beroepsgerigte opgeleides in die geesteswetenskaplike studierigtings dit ná hul opleiding in die beroepsituasie tref:

Soos u moontlik weet, word daar in die Nasionale Instituut vir Mannekragnavorsing van die RGN op 'n baie omvattende skaal navorsing gedoen oor die hoëvlakmannekrag van ons land. Met nagenoeg 150000 gegradueerdes word daar kontak behou. In 1978 is 'n opname onder pasgegradueerdes onderneem om te bepaal hoe hulle hul werksituasie ervaar. Altesaam 4855 pasgegradueerdes wat in besit van 'n eerste B-graad is, het aan die opname deelgeneem. Veral interessant was die antwoorde van daardie pasgegradueerdes wat na die verkryging van hul graad gaan werk het en wat nog nie voorheen ervaring van werk, behalwe vankansiewerk, gehad het nie. 
Die prentjie wat uit hierdie opname na vore gekom het, is die volgende: Van diegene met algemene grade in die geesteswetenskappe het byna 50 persent in beroepe beland waarvoor formeel ' $n$ mindere $k$ walifikasie as hulle s'n vereis word. By die beroepsgerigte grade was hierdie persentasie gelukkig laer, nl. 36 persent. Oor die algemeen het diegene met beroepsgerigte grade in ' $n$ groter mate in beroepe beland waarvoor 'n B-graad wel vereis word, as diegene met algemene grade in Lettere en Wysbegeerte, $\mathrm{nl} .54$ persent teenoor 36 persent. 'n Interessante tendens is voorts dat diegene met grade in die Lettere en Wysbegeerte en wat in die openbare sektor 'n betrekking aanvaar het, in 'n effens groter mate as diegene in die private sektor gevoel het dat hulle beroep wel die kwalifikasies waaroor hulle beskik benut. Samevat tend kan dus aan die graduandi gesê word dat 'n relatief groot aantal van $u$ in ' $n$ beroepsituasie gaan beland of moontlik reeds beland het waarin $u$ sal voel dat $u$ opleiding nie ten volle benut word nie. Daarteenoor sal 'n aantal van $u$, gelukkig ' $n$ baie klein groep, voel dat $u$ opleiding $u$ nie opgewasse maak vir $u$ taak nie. In vergelyking met opleiding in die farmakologie, tandheelkunde, ingenieurswese en die natuur- en landboukundige wetenskappe, voel die gegradueerdes van 'n fakulteit Lettere en Wysbegeerte hulle in 'n veel mindere mate pasklaar vir die beroepe waarvoor hulle opgelei is. Hulle voel hulle egter wel in 'n relatief hoë mate opgewasse vir hul taak.

Uit 'n analise van die genoemde pas-gegradueerdes se antwoorde op die vraag in watter mate hulle hul universiteitsopleiding in hul werk benut, is daar betekenisvol meer beroepsgerigte opgeleides van die fakulteite Lettere en Wysbegeerte wat voel dat hul opleiding in 'n groot mate in hul werk aangewend word, as wat die geval is met diegene wat 'n algemene opleiding in Lettere en Wysbegeerte deurloop het.

In die navorsing van die Nasionale Instituut vir Mannekragnavorsing van die RGN is daar ook gesoek na aanduidings waarom formele opleiding min of glad nie in die latere beroepsbeoefening gebruik wor' nie. Ongelukkig is hierdie aanduidings t.o.v. 'n groot spektrum van beroepe nie beskikbaar nie. In 'n ondersoek na argitekte het met verwysing na spesifieke fasette van die opleiding, nl. die voorbereiding t.o.v. tegnologie (d.w.s. die toepassing van wetenskaplike beginsels in die praktyk) en praktykopleiding die skerpste aanklagte na vore gekom: Wat die gebruik van tegnologie betref, word die oorspronklike formele opleiding as verouderd bestempel en t.o.v. die tegnologie en praktykopleiding is die opleiding in 'n hoë mate as onvoldoende bestempel. 
Bexocpsopleiding: 'n gedugte taak

Teen die voorafgaande agtergrond kan daar nou opsommend sekere implikasies vir beroepsopleiding uitgelig word.

Eerstens: die probleem van beroepsgerigte opleiding kan nie net opgelos word deur 'n sogenaamde gesonde balans tussen die beroepsgerigte en nie-beroepsgerigte komponente van die opleiding nie. Trouens, al te dikwels word daar in opleiding aanvaar dat studente spontaan die verskillende komponente van 'n leergang sal integreer soos dit deur die ontwerpers van die leergang en die dosente bedoel is. Om dit te aanvaar, blyk totaal ongeregverdig te wees. Die enigste didakties-verantwoorde oplossing sal gesoek moet word in leerstofkeuse wat direk die toekomstige beroepsituasies op 'n wetenskaplik-verantwoorde wyse moet kan orden. Dit impliseer toegespitsde beroepsgerigte kursusse vir elke beroepsopleiding. So 'n verskeidenheid kursusse kan deur geen universiteit, gesien die subsidiereëlings en gesien die mannekragsituasie in die RSA, verwesenlik word nie. Wanneer die leerstofkeuse geselekteer word uit die toekomstige beroepsituasie, dan beteken dit nog nie dat die universiteit in sy beroepsgerigte opleiding tot toegepaste wetenskapsbeoefening gedwing word nie. Fundamentele wetenskaplike vorming van studente is moontlik aan die hand van 'n verskeidenheid inhoude, dus ook spesifiek beroepsgerigte inhoude. Elke leerplaninhoud leen hom vir verskillende vlakke van wetenskaplike ordening, met gevolglike vlakke van weteriskaplike gevormdheid van die studente.

Dat daar opnuut grondig besin sal moet word oor beroepsgerigte opleiding aan universiteite, gesien die uitdruklike standpuntstelling van toegepaste wetenskapsbeoefening en die oorwegend beroepsgerigte opleiding aan technikons, en gesien hul geweldige sterk groei, ly geen twyfel nie. Die sterk groei van die technikons impliseer dus nie net dat daar binne die technikongeledere gedink moet word oor hul aard en taak nie, maar die universiteite word eweneens by implikasie in sy wese geraak deur die dinamiek in die technikons.

Tweedens: 'n probleem wat feitlik konsekwent by veral beroepsgerigte opleiding onderskat word, is die vermoë van opgeleides om sekere wetenskaplike insigte in die praktyk te kan toepas. Om insigte te kan verwerf en weer te gee, vereis 'n ander intellektuele aktiwiteit as om daardie insigte innovatief in praktiese situasies te kan aanwend. Ai te dikwels word aanvaar dat die wetenskaplik-gevormde persoon ook sy kennis sal kan toepas in 'n verskeidenheid praktiese situasies. Indien die toepassings- of innovasie-idee, d.w.s. die tegnologie, nie uitdruklik as 'n opleidingsdoelwit nagestre ef word nie, kan dit maklik gebeur dat die opgeleide die praktiese beroeps- 
opset nie die hoof kan bied nie. Die klassieke akademiese vorming wat berus op 'n strewe na diep insig en wat lei tot die vermoë om sake indringend te kan verklaar, lei dus nie spontaan tot die vermoë om in die praktyk doeltreffend op te tree nie. Waar die beheersing van die tegnologie in die natuurwetenskaplike beroepsgerigte opleiding reeds een van die hoofknelpunte in die opleiding is, is dit nog veel meer in die geesteswetenskaplike beroepsgerigte opleidings die geval.

Derdens: in 'n vinnig-veranderende wêreld moet studente ook só opgelei word dat hulle genoeg openheid en soepelheid sal besit om in die werksituasie waarin hulle sal beland nie net by die veranderende omstandighede te kan aanpas nie, maar ook leiding sal kan neem in die kanalisering en akkommodering van veranderings. Dit is natuurlik makliker gesê as gedoen, want meeste veranderings wat sal plaasvind of situasies waarin studente gaan beland, is nie voorsienbaar nie. Daar is veral die volgende wyses waarop by studente hierdie sleutelvaardighede aangekweek kan word: Eerstens is daar geen plaasvervanger nie vir 'n werklik fundamentele streng dissiplinegeoriënteerde skoling in 'n basiese wetenskap. Hierdeur word aan 'n student ' $n$ duidelike verwysingsraamwerk gegee van waaruit nuwe probleme benader kan word. Dit gee wetenskaplike identiteit en sekerheid en dit vorm die voorwaarde vir samewerking binne inter- of multi-dissiplinêre of selfs multi-professionele spanne. In so 'n basiese skoling mag daar egter nooit eksklusiwiteit of selfs vyandigheid ten opsigte van ander wetenskappe of beroepsgerigte opleidings gepredik word nie. Tweedens moet daar in doseerwerk naas 'n gerigtheid op begryping en verklaring ook in 'n groter mate ' $n$ innoverende aanpak of tradisie gevestig word. Dit impliseer dat besondere klem in die opleiding op die implikasies of sêkrag van wetenskaplike feite en verbande geplaas moet word. So 'n opleiding sal makliker daartoe lei dat opgeleides tot innovasie geneig sal wees, wat op sy beurt tot ' $n$ hoër vlak van professionalisering sal lei. Derdens moet daar selfs vanaf die eerste jaar by die student 'n navorsende ingesteldheid aangekweek word. Die vinnige tempo waarteen nuwe tegnologie ontwikkel en die hoë tempo van veranderings wat plaasvind, bring mee dat daar'n groot behoefte aan navorsing gaan ontstaan. Die kritiese knelpunt is egter nie soseer geleë in die nie-beskikbaarheid van navorsingsresultate nie, maar veel meer in die gebrek aan infrastruktuur binne beroepsverband vir die implementering van navorsingsbevindings. Hier veral vervul die universitêr-opgeleide 'n sleutelrol. Vir hierdie rol en vir die gevoeligheid vir die implikasies van navorsingsbevindings moet daar in beroepsopleiding spesifiek voorsiening gemaak word. Vierdens moet daar eenvoudig 'n openheid aangekweek word vir 'n inter-dissiplinêre en 'n inter-professionele aanpak. Niemand wat al op hierdie terrein gewerk het, sal die probleme wat ten opsigte hiervan oorbrug moet word, onderskat nie. Laastens moet in beroepsopleiding by die studente 'n aan- 
voeling van die toekomsdimensie aangekweek word. Met 'n sensitiwiteit vir die implikasies van bepaalde tendense sal daar gelyktydig ook 'n groter openheid bewerkstellig word vir die noodsaak van voortdurende kritiese beoordeling van die beroepsituasie met die oog op die mak van moontlike aanpassings.

Ten slotte staan die feit van voortdurende onderwys by alle vorme van beroepsopleiding baie prominent. Aan hierdie verantwoordelikheid sal universiteite hul nie kan onttrek nie.

\section{Gelukwense aan die graduandi}

Teen die agtergrond van my gedagtegang tot dusver, kan ek veral aan $u$ wat vanaand beroepsgerigte grade of diplomas ontvang, die volgende wens rig: Hartlik geluk met hierdie mylpaal in u lewe. Mag dit die begin wees van 'n mooi beroepsloopbaan vir $u$. Indien $u$ 'n stewige wetenskaplike gevormdheid aan die PU ontvang het, daar by $u$ 'n gevoeligheid aangekweek is vir wat die seggingskrag van kennis en begrippe in werklikheid is, $u$ 'n openheid het ten opsigte van wat ander dissiplines of professies kan bied, $u$ 'n aanvoeling het van die tegnologie wat in u besondere beroep meespeel, $u$ met openheid veral vir navorsingsbevindings krities sal bly kyk na u beroepsituasie, en u sal bly speur na dit wat die toekoms mag inhou en die implikasies daarvan, dan voorsien ek vir $u$ 'n opwindende beroepsloopbaan waarin u nie in die graf van die groef sal verval nie. Ek wens u natuurlik ook 'n baas toe wat nie alreeds in die graf van die groef beland het nie!

\section{Bibliografie}

BOI.I.Y, B.A. 1976. Crossfire in professional education: students, the professions and society. New York: Pergamon Press.

GARBERS, J.G. en VAN AARDE, J.II. 1974. 'n Generasie standerd X-leerlinge. Port Elizabeth: U.P.E., Navorsingspublikasie C4.

JACOBSZ, F.P. 1977. Die aanspraak van die beroepswêreld op die universiteit. In: U.P.E. 1977. Die uitdaging aan die moderne universiteit. Publikasicrecks B3. Port Elizabeth. U.P.F.

KOMITEF, VAN UNIVERSITEITSHOOFIDE. 1979. I Die oorgang van skool na universiteit; verrigtinge van die Nasionale Simposium, Pretoria, 18 - 19 September 1978 . 
MAYHEW, L.B. 1971. Changing practices in education for the professions. Atlanta, Georgia: Southern Regional Education Board.

PAUW, J.R. 1973. Die noodsaaklikheid van vernuwing in 'n veranderende wêreld. In: R.A.U., 1973 Vernuwing in die universiteit in die jare '70 en '80. Johannesburg: R.A.U., bl. $6 \cdot 24$.

RAU, 1973. Vernuwing in die universiteit in die jare '70 en ' 80 . Johannesburg: RAU.

SCHEIN, E.H. and KOMMERS, D.W. 1972. Professional education: some new directions. New York: McGraw-Hill.

WOLFF, R.P. 1969. The ideal of the university. Boston: Beacon Press. 